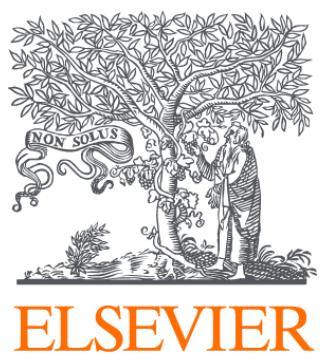

Since January 2020 Elsevier has created a COVID-19 resource centre with free information in English and Mandarin on the novel coronavirus COVID-

19. The COVID-19 resource centre is hosted on Elsevier Connect, the company's public news and information website.

Elsevier hereby grants permission to make all its COVID-19-related research that is available on the COVID-19 resource centre - including this research content - immediately available in PubMed Central and other publicly funded repositories, such as the WHO COVID database with rights for unrestricted research re-use and analyses in any form or by any means with acknowledgement of the original source. These permissions are granted for free by Elsevier for as long as the COVID-19 resource centre remains active. 


\title{
An accelerated shift in the use of remote systems in epilepsy due to the COVID-19 pandemic
}

\author{
Mathieu Kuchenbuch $^{\mathrm{a}, \mathrm{b}}$, Gianluca d'Onofrio ${ }^{\mathrm{a}, \mathrm{c}}$, Elaine Wirrell ${ }^{\mathrm{d}}$, Yuwu Jiang ${ }^{\mathrm{e}}$, Sophie Dupont ${ }^{\mathrm{f}, \mathrm{n}}$, \\ Zachary M. Grinspan ${ }^{\mathrm{g}}$, Stephane Auvin ${ }^{\mathrm{h}}$, Jo M. Wilmshurst ${ }^{\mathrm{i}}$, Alexis Arzimanoglou ${ }^{\mathrm{j}, \mathrm{k}}$, J. Helen Cross $^{1}$, \\ Nicola Specchio ${ }^{\mathrm{m}}$, Rima Nabbout ${ }^{\mathrm{a}, \mathrm{b}, *}$
}

a APHP, Reference Centre for Rare Epilepsies, Department of Pediatric Neurology, Hôpital Necker-Enfants Malades, Université de Paris, Paris, France

${ }^{\mathrm{b}}$ Laboratory of Translational Research for Neurological Disorders, INSERM UMR 1163, Imagine institute, Université de Paris, France

c Pediatric Residency Program, Department of Women and Child Health, University of Padua, Italy

d Divisions of Child and Adolescent Neurology and Epilepsy, Department of Neurology, Mayo Clinic, Rochester, MN, USA

e Departments of Pediatrics and Pediatric Epilepsy Center, Peking, University First Hospital, Beijing, China

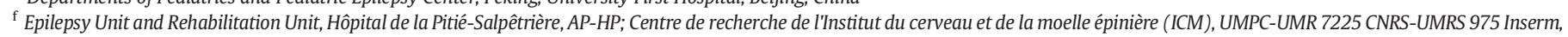
Paris, France

${ }^{g}$ Departments of Population Health Sciences and Pediatrics, Weill Cornell Medicine, New York, NY, USA

${ }^{\mathrm{h}}$ APHP, Department of Pediatric Neurology, Hôpital Robert-Debré, Paris, France

i Paediatric Neurology Department, Red Cross War Memorial Children's Hospital, Neuroscience Institute, University of Cape Town, South Africa

j Department of Paediatric Epilepsy, Sleep Disorders and Functional Neurology, University Hospitals of Lyon, Member of the ERN EpiCARE, Lyon, France

${ }^{\mathrm{k}}$ Epilepsy Unit, San Juan de Dios Children's Hospital, Universitat de Barcelona, Member of the ERN EpiCARE, Barcelona, Spain

${ }^{1}$ UCL NIHR BRC Great Ormond Street Institute of Child Health, London WC1N 1EH, United Kingdom of Great Britain and Northern Ireland

${ }^{\mathrm{m}}$ Rare and Complex Epilepsy Unit, Department of Neuroscience, Bambino Gesu' Children's Hospital, IRCCS, Member of European Reference Network EpiCARE, Rome, Italy

${ }^{\mathrm{n}}$ Université Paris Sorbonne, Paris, France

\section{A R T I C L E I N F O}

\section{Article history:}

Received 14 July 2020

Revised 24 July 2020

Accepted 24 July 2020

Available online 31 August 2020

\section{Keywords:}

Telemedicine

E-health

E-learning

Virtual meeting

Remote work system

Teleconsultations

\begin{abstract}
A B S T R A C T
Purpose: The purpose of the study was to describe epileptologists' opinion on the increased use of remote systems implemented during the COVID-19 pandemic across clinics, education, and scientific meetings activities.

Methods: Between April and May 2020, we conducted a cross-sectional, electronic survey on remote systems use before and during the COVID-19 pandemic through the European reference center for rare and complex epilepsies (EpiCARE) network, the International and the French Leagues Against Epilepsy, and the International and the French Child Neurology Associations. After descriptive statistical analysis, we compared the results of France, China, and Italy.

Results: One hundred and seventy-two respondents from 35 countries completed the survey. Prior to the COVID-19 pandemic, 63.4\% had experienced remote systems for clinical care. During the pandemic, the use of remote clinics, either institutional or personal, significantly increased $\left(\mathrm{p}<10^{-4}\right)$. Eighty-three percent used remote systems with video, either institutional (75\%) or personal (25\%). During the pandemic, $84.6 \%$ of respondents involved in academic activities transformed their courses to online teaching. From February to July 2020, few scientific meetings relevant to epileptologists and routinely attended was adapted to virtual meeting (median: 1 [25th-75th percentile: 0-2]). Responders were quite satisfied with remote systems in all three activity domains. Interestingly, before the COVID19 pandemic, remote systems were significantly more frequently used in China for clinical activity compared with France or Italy. This difference became less marked during the pandemic.

Conclusion: The COVID-19 pandemic has dramatically altered how academic epileptologists carry out their core missions of clinical care, medical education, and scientific discovery and dissemination. Close attention to the impact of these changes is merited.
\end{abstract}

(c) 2020 Elsevier Inc. All rights reserved.
Abbreviations: SARS, severe acute respiratory syndrome; EpiCARE, European reference network for rare and complex epilepsies; ILAE, International League Against Epilepsy; ICNA, International Child Neurology Association.

* Corresponding author at: Reference Centre for Rare Epilepsies, Department of Pediatric Neurology, Necker Enfants Malades Hospital, 149 rue de Sèvres, 75015 Paris, France.

E-mail address: rimanabbout@aphp.fr (R. Nabbout).

\section{Introduction}

Pandemics can lead to government regulations that limit social contact, decreased access to healthcare resources, and increased anxiety and fear - all can disrupt the care path of patients with chronic diseases and decrease of face-to-face visits. In 2003, a study on the outbreak of 
severe acute respiratory syndrome (SARS) in China showed that the loss of contact with medical care providers led to an increase in the withdrawal of antiseizure medications resulting in an increase in seizure frequency [1]. The current COVID-19 pandemic is an important challenge for the management of patients with epilepsy worldwide. Remote patient management systems [2] (in use since the 1990s and now integral to several national digital health strategies [3-6]) are a valuable tool during a pandemic to continue medical follow-up. They include different types of communications such as phone calls, one-way video links, and on live interactive communication. In addition, the epilepsy medical community is involved in educational activity and promoting knowledge dissemination through courses and scientific congresses. These activities also rely on face-to-face interactions and are also likely affected by the COVID-19 pandemic.

The aim of this study was to assess the impact of the COVID-19 pandemic on the acute use of remote systems in clinics, education, and scientific meetings in the field of epilepsy and to explore the users' satisfaction and the perspectives of future use.

\section{Methods}

We conducted a cross-sectional, electronic survey of epileptologists, neurologists, and pediatric neurologists mainly involved in the epilepsy field to determine the use of remote work during the COVID19 pandemic (supplementary data). To reach a wider public, this survey was addressed to adult and child neurologists specialized in epilepsy care through the European reference network for rare and complex epilepsies (EpiCARE), International League Against Epilepsy (ILAE), International Child Neurology Association (ICNA), the French League against Epilepsy (LFCE), and the French Society of Child Neurology (SFNP). The survey was comprised of 60 questions divided into four sections: demographic and general information followed by remote work for clinical practice, education, and scientific meetings and symposia (for details, see supplementary data). Items assessed practice before and during the COVID-19 pandemic. The first two sections were mandatory (demographics and clinical practice). We used different types of questions: closed $(n=60)$, semiopen $(\mathrm{n}=12)$, and open $(\mathrm{n}=12)$. Some questions used semiquantitative scales such as the Likert scale.

Descriptive statistics included mean \pm standard deviation for normal data, and median [25th-75th percentile] for non-normal data. In the event of missing data, percentages were calculated per number of responses obtained, item by item. Frequency of use of remote system was scored as follows: never $=0$, used it once $=0.5$, few $=1$, monthly $=2$, weekly $=3$, and daily $=4$. Wilcoxon signed-rank test were used to compare the frequency of the institutional and personal remote system use before and during the COVID-19 pandemic and the frequency of use of these two systems during the same period. Open-ended questions on free text allowed us to obtain qualitative data to illustrate respondents' feelings about their satisfaction with remote systems. We constructed a coding frame to analyze free-text data about satisfaction of remote clinic, online teaching, and virtual meeting. We subdivided into level categories to evaluate positive and negative aspects with some subcategory: cost, time, interaction, and target public. Two authors (MK and $\mathrm{RN}$ ) discussed the coding and interpretation of results.

Finally, we compared findings among the three countries with the highest number of respondents (France, China, and Italy). Quantitative or semiquantitative data were compared using Kruskal-Wallis $\mathrm{H}$ test followed, in case of significance $(p<0.05)$, by a Dwass-SteelCritchlow-Fligner procedure. For qualitative data, we used $\mathrm{Chi}^{2}$ tests. A p-value $<0.05$ was considered as statistically significant, and a p-value $<0.1$ as a tendency. The statistical analyses were performed using R software [7].

This study was approved by the ethics committee of our institution Necker Hospital, APHP. Participants were entirely free to participate and their consent was implicit.

\section{Results}

\subsection{General information}

Between April 6 and May 13, 2020, 172 respondents in 35 countries from 5 continents completed the survey from all over the word (Table 1, Fig. 1). Responders were involved in caring for children with epilepsy ( $n=111,64.5 \%$ ), adults ( $n=48,27.9 \%$ ), or both $(n=13,7.6 \%)$. One hundred and fifty $(87.2 \%)$ worked in a public hospital. All had a clinical practice, 91 were involved in clinical research (52.9\%), and 27 in basic research activities (15.7\%). Most of the participants were from Europe $(n=121,70.4 \%)$. A containment policy due to the COVID-19 pandemic was decreed in the countries of 166 participants (96.5\%). Indeed, 129 participants (75\%) belonged to the 15 most impacted countries of the world in this period [8]. The sections concerning remote work for education and scientific meetings were completed by 160 participants (93\% of all respondents). The questionnaire completion rate was $97 \%(302 / 10,150)$.

\subsection{Remote technology for clinical practice}

Prior to the COVID-19 pandemic, 109 responders (63.4\%) had already experienced using a personal $(84 / 109,77.1 \%)$ or an institutional $(89 / 109,81.7 \%)$ remote system: $64 / 109$ for patient direct care (58.7\%), 43 for education of trainees (39.4\%), 31 for clinical case discussions within other institutions (28.4\%), 40 for research (36.7\%), and 13 for clinical case discussions within their own institutions (11.9\%). For 76 on the 172 responders (44.2\%), this experience was at least monthly using institutional ( $n=64 / 76,84.2 \%)$ or personal ( $\mathrm{n}=51 / 76,67.1 \%$ ) remote systems (Fig. $2 \mathrm{~A}$ ). There was no statistical difference between the frequency of use of institutional versus personal remote system $(\mathrm{p}=0.2)$. The three main personal systems used were Skype ${ }^{\circledR}(\mathrm{n}=49$ of the 89 using personal remote system, $55.1 \%), Z$ Zoom $\AA(n=43,48.3 \%)$, and Webex $\AA(n=15,16.9 \%)$. The means frequently used to contact remote respondents in an emergency were telephone calls ( $\mathrm{n}=134,78 \%$ ) and e-mails from families (126, 73\%). Other means (letters from families $(37,21.5 \%)$ and letters $(71,4.3 \%)$, telephone calls $(74,43 \%)$, and e-mails $(88,51.2 \%)$ from the attending physician) were less frequently used.

During the COVID-19 pandemic, the use of remote systems increased, both institutional systems (89 to 139) and personal systems

Table 1

Demographic, professional, and type of activity characteristics.

\begin{tabular}{llll}
\hline \multirow{3}{*}{ Sex } & $\mathrm{n}$ & $\mathrm{n}($ total = 172) & $\%$ \\
\hline \multirow{4}{*}{ Continent } & Male & 69 & 40.1 \\
& Female & 103 & 59.9 \\
& South America & 6 & 3.5 \\
& North America & 9 & 5.2 \\
& Africa & 3 & 1.7 \\
& Asia & 33 & 19.2 \\
& Europe & 121 & 70.4 \\
& 30-40 & 32 & 18.6 \\
& 40-50 & 65 & 37.8 \\
& 50-60 & 50 & 29.1 \\
& 60-70 & 23 & 13.4 \\
& $>70$ & 2 & 1.2 \\
& Children & 111 & 65.4 \\
& Adult & 48 & 57.9 \\
& Both & 13 & 7.6 \\
& Public & 150 & 87.2 \\
& Private & 2 & 12.2 \\
& Implicated in care networks & 95 & 55.2 \\
& Clinical & 172 & 100 \\
& Clinical research & 91 & 52.9 \\
& Academic & 88 & 51.2 \\
& Basic research & 27 & 15.7 \\
& & &
\end{tabular}




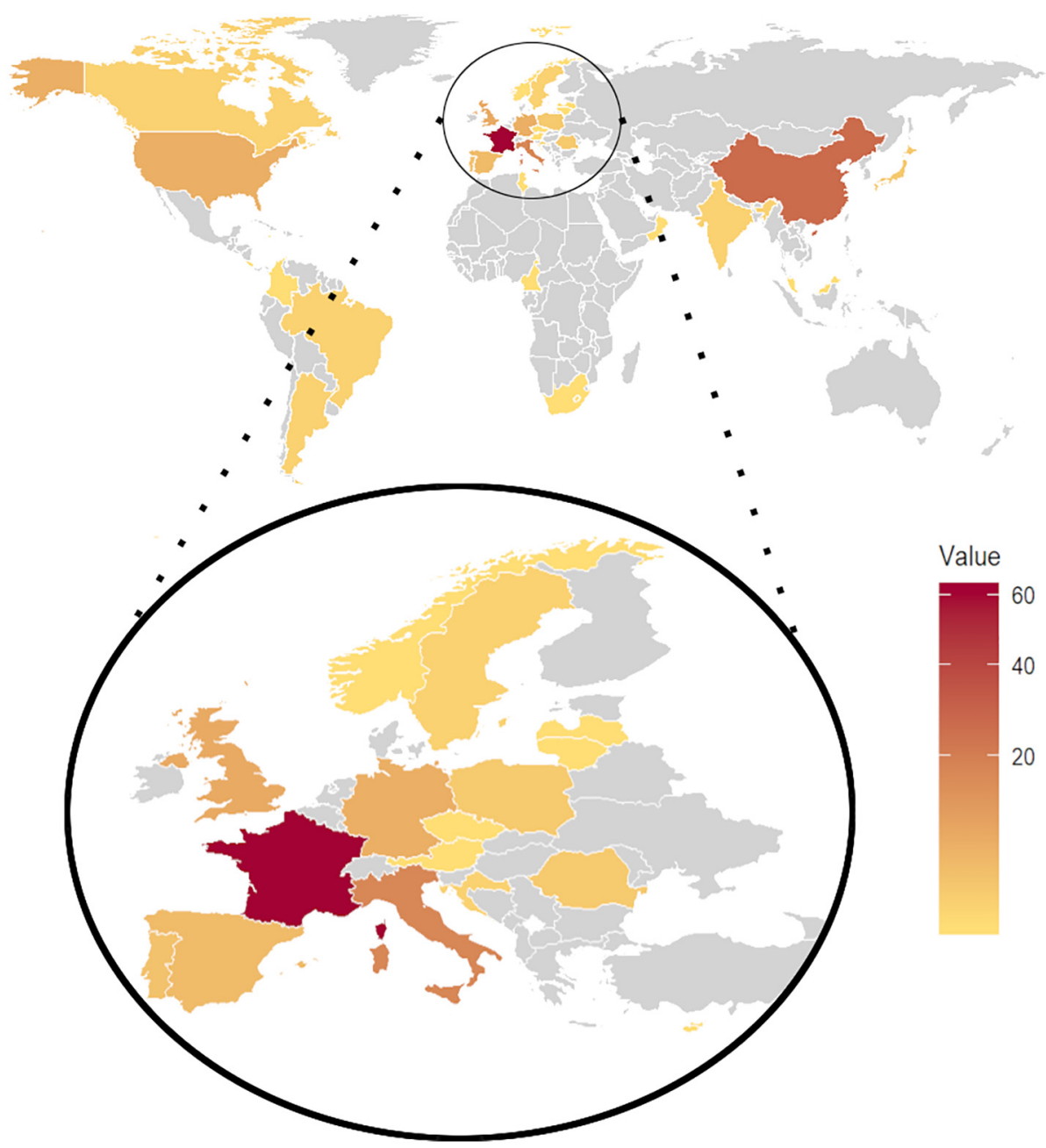

Fig. 1. Countries of the respondents around the world.

(84 to $114 ; \mathrm{p}<0.001$ for both comparisons). One hundred and fortyseven utilized them at least monthly (85.5\%) with institutional (130/ $147,88.4 \%)$ or personal systems (96/147, 65.3\%, Fig. 2B). However, contrary to the pre-pandemic period, the use of institutional remote systems was significantly higher than that of personal systems $(p=0.001)$. Only one respondent from China did not have to reschedule any face-to-face clinics compared with 138 who rescheduled most or all their clinics (80.3\%). One hundred and sixty-two respondents (94.2\%) replaced faceto-face visits by various ways of remote connections with the families or the patients. This involved all clinics for $32(19.8 \%)$, most of them for $98(60.5 \%)$ and only a few for 32/162 respondents (19.8\%). Sixty-eight (42\%) used phone calls without any remote specific connection with or without video, and 135 a remote system with video connection (83.3\%). This system was institutional for 101 (74.8\%) either regularly available (50/101, 49.5\%) or developed for this pandemic (51, 50.5\%). A personal remote system was used by 34 (25.2\%). The duration of remote clinics was considered as identical as face-to-face ones for 50 respondents (31.1\%), shorter for 77 (47.8\%, including much shorter for 13$)$, and longer for 34 (21.1\%, including much longer for 6$)$. Regarding antiseizure medication changes, $50.9 \%$ of respondents tended to make fewer amendments $(n=83), 45.4 \%$ same $(n=74)$, and $3.7 \%$ more $(n=6)$. Electroencephalogram (EEG) were less frequently requested for $65.6 \%(n=107)$, without changing the frequency requested for $30.1 \%(n=49)$, and more frequently requested for $4.3 \%(n=7)$. Blood test were less frequently requested for $52.8 \%(\mathrm{n}=86)$, without changing the frequency requested for $42.3 \%(n=69)$, and more frequently requested for $4.9 \%(n=8)$.
Respondents reported an increase in email and phone contacts by patients and their families (for 116, 67.4\% and 104, 60.5\% of respondents, respectively) but also by primary care physicians (for $45,26.2 \%$ and 64 , $37.2 \%$, respectively for email and phone).

\subsection{Remote technology for educational purpose}

One hundred and thirty-four respondents $(134 / 160,83.8 \%)$ were involved in educational activities. Before the COVID-19 pandemic, 131 (97.8\%) had face-to-face lectures or small group teaching courses, and 76 (56.7\%) had been involved in online teaching. Educational activities were impacted by the COVID-19 pandemic for 117 respondents (87.3\%). Eighty-two percent had at least a part of their activities canceled ( $n=96 / 117,82 \%$ ), postponed ( $n=43,36.8 \%$ ), or transformed to online teaching $(99,84.6 \%)$. Respondents' courses were either interactive $(24 / 99,24.2 \%)$, video recorded $(17 / 99,17.2 \%)$, or both $(52 / 99$, $52.6 \%)$. For $40 / 99$ respondents, all courses were transformed to online teaching $(40.4 \%)$.

\subsection{Remote technology for meeting and symposia}

Before the COVID-19 pandemic, 62.9\% (83/132) of the respondents had participated in remote scientific meetings, $57.6 \%$, (72/125) in workshops, 48.2\% (53/110) in clinical studies meetings, and 37.1\% (39/105) in research symposia. Few had such experience with national 9.8\% $(13 / 132)$ or international 9.1\% (11/121) congresses. During the period 


\section{A. Frequency use before COVID-19 pandemic}

Institutional remote work system

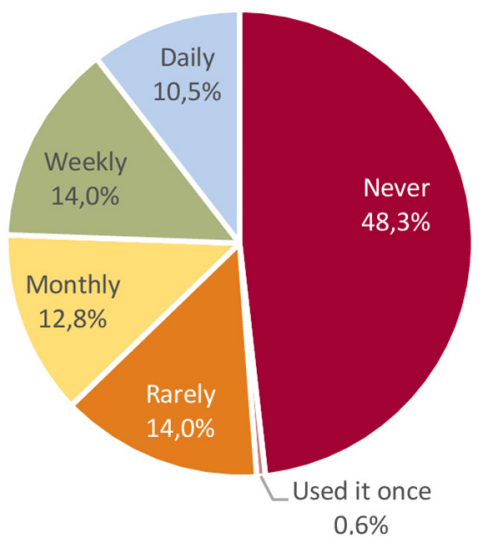

Personal remote work system

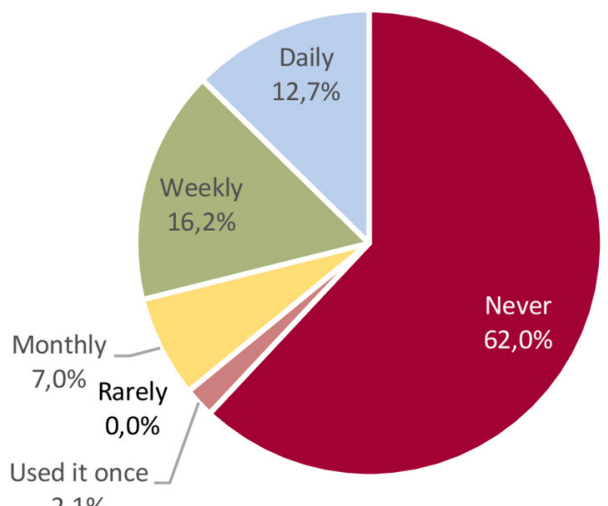

$2,1 \%$

\section{B. Frequency use during COVID-19 pandemic}

Institutional remote work system

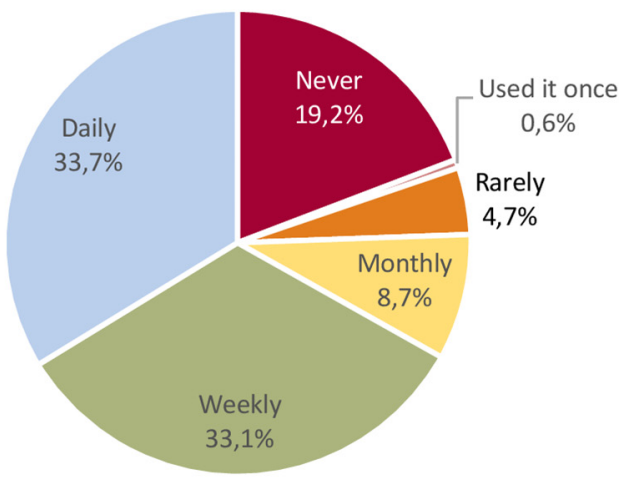

Personal remote work system

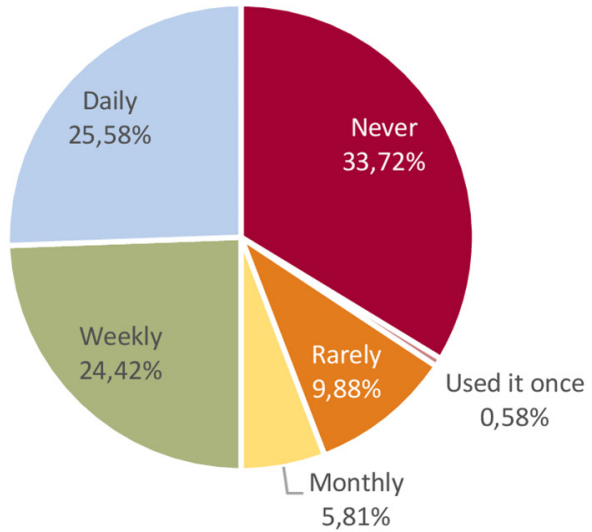

Fig. 2. Frequency of use of the institutional (left side) and personal (right side) remote work systems for telemedicine before (A) and during (B) the COVID-19 pandemic.

from February to July 2020, responders had planned 4 [3-7] meetings. Only a few were transformed to remote (median: $1[0-1.5]$ ) giving the opportunity to eighty-nine responders (67.4\%) who participated in at least one meeting transformed to remote. The rest of the meetings were canceled or postponed.

\subsection{Respondents' satisfaction about remote systems use}

Sixty-one percent of respondents were satisfied by their remote clinics (99/162, including 17 very satisfied), $56.7 \%$ by their online teaching (55/99, including 8 very satisfied), and $45.2 \%$ by remote meetings (57/126) (Fig. 3). Feelings regarding family and patient satisfaction with the remote clinic were positive for $72.2 \%$ of the respondents (118/162, of which 18 were very positive) and $51.5 \%$ regarding students and online teaching (51/99, of which 6 were very positive). Almost onequarter of responders reported dissatisfaction with remote work, mostly for remote education ( $22.9 \%, \mathrm{n}=22 / 99)$, remote meetings (18\%, 22/126), and remote clinics (23/162, 14.3\%).

Respondents indicated they would likely continue greater use of remote work for remote clinics, education, and meetings after the COVID19 pandemic, in $81.2 \%$ (121/149), 62.9\% (61/97), and 54.7\% (87/159), respectively (Fig. 4). Free text allowed us to have more qualitative data on the reasons to maintain remote working in their different activity axis.
Indeed, in their opinion, remote clinics had the advantage of decreasing time and cost for families and patients travel and consequently of work absenteeism. This was highlighted for follow-up visits but not for new patients having their first evaluation. For first visits, respondents declared a clear need for a face-to-face visit. Saving time, adapting to the availability of students, and increasing the target audience due to the absence of the need to travel to attend the course seemed to be the positive factors identified by respondents regarding remote education. However, they identified several negative factors including a decrease in interactions, especially the immediate students' feedback reactions. Workshops with a small number of participants was reported as particularly adapted to remote systems allowing a gain in term regarding travel, time, and cost. However, respondents agreed that national and international meetings are more adapted to in-person meetings as their major goal in addition to disseminate knowledge is to favor personal interactions and consolidate personal friendships and contacts to enhance collaboration and exchange of ideas.

\subsection{Comparisons between France, China, and Italy}

The pandemic began in December 2019 in China, late February 2020 in Italy, and early March in France. These countries were all placed under quarantine (from 23 January to 8 April 2020 in China, from 9 March to 4 May in Italy and from 16 March to 11 May in France). The peak of pandemic-related deaths occurred between February 14, 2020 


\section{Satisfaction about remote systems}

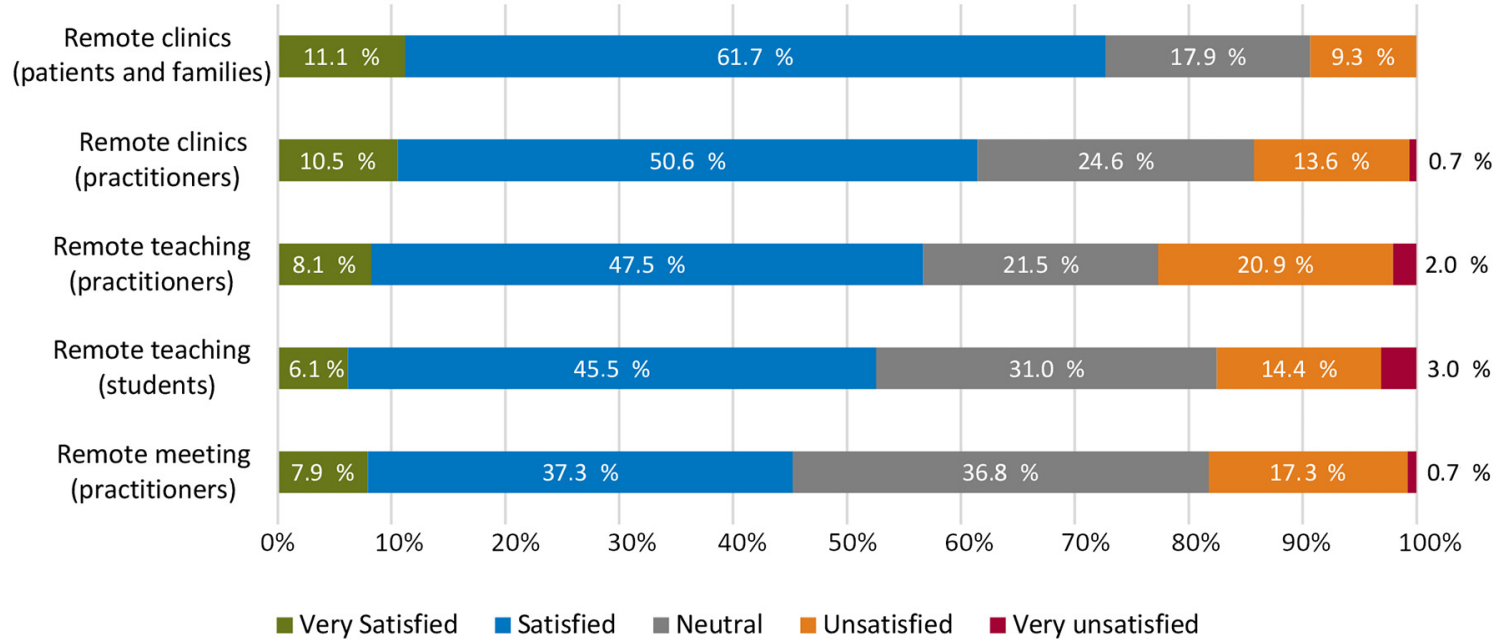

Fig. 3. Respondents' views on the satisfaction of remote systems use (the participant under consideration is put in brackets).
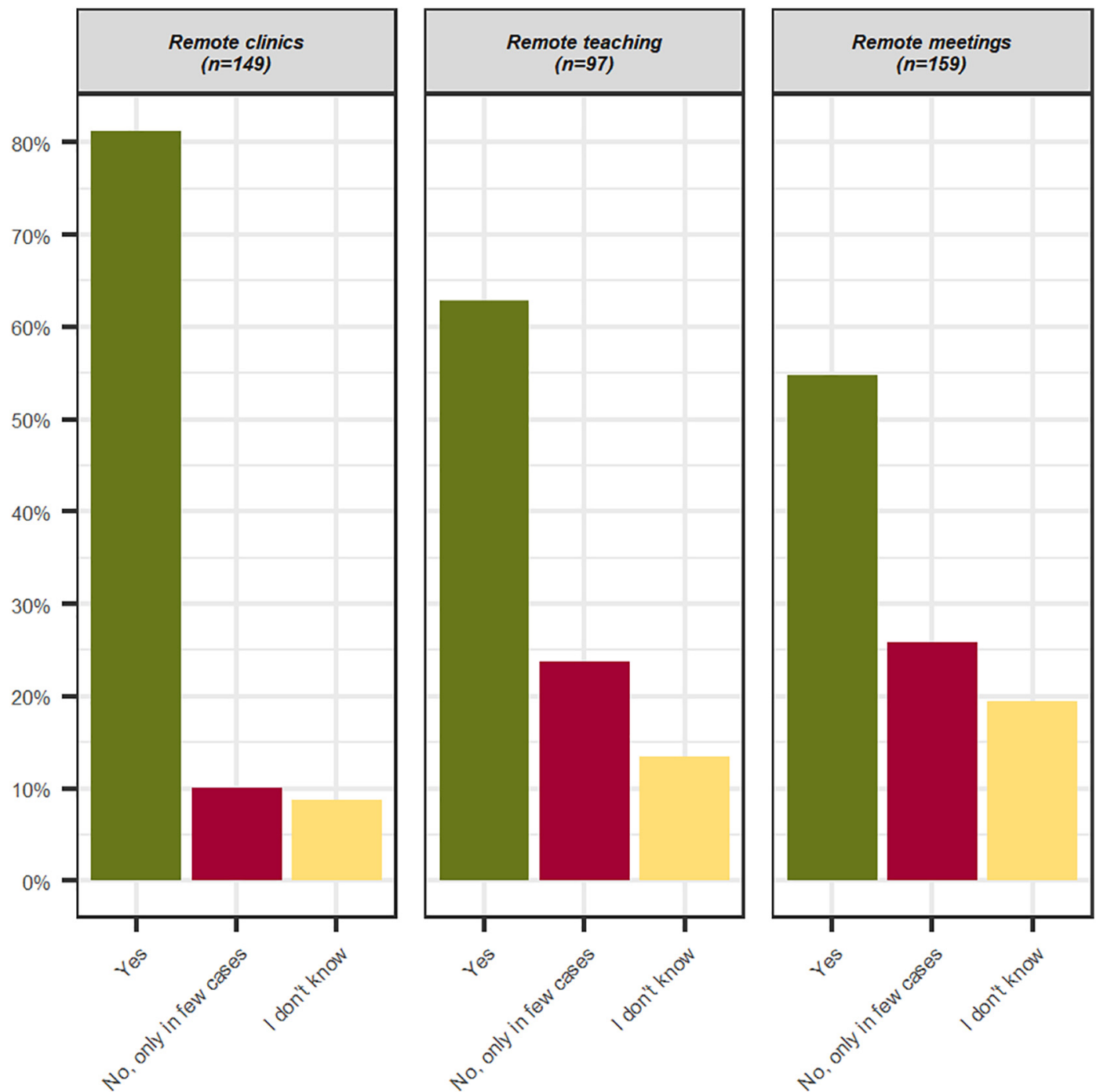

Fig. 4. Respondents' views on the future use of remote systems after the COVID-19 pandemic in the field of remote clinics, education, and scientific meetings. 
(143 deaths in $24 \mathrm{~h}$ ) in China, March 27 in Italy (919 deaths in $24 \mathrm{~h}$ ), and April 15 in France (1438 deaths in 24 h) [9].

Comparison of data from France $(n=60)$, Italy $(n=16)$, and China $(n=24)$ showed no significant differences in terms of age, gender, and practice (pediatric, adult, or both, public or private, epilepsy center or not). Belonging to a healthcare network was statistically different between countries $\left(\mathrm{p}<10^{-4}\right)$. Indeed, only four Chinese respondents (16.7\%) belonged to a patient care network, whereas there were $50 \%$ in France (30 responders) and 87.5\% in Italy (14).

Before the COVID-19 pandemic, the rate of respondents who had experienced remote working systems was higher in China than in the two other countries (91.6\% versus $61.7 \%$ for France and $25 \%$ for Italy, $\left.\mathrm{p}=10^{-4}\right)$. In the same way, the number of respondents with an institutional remote work system was higher in China (65.5\% versus $45 \%$ for France and $12.5 \%$ for Italy, $\mathrm{p}<10^{-4}$ ). However, the rate of respondents who had a personal remote work system was not statistically different (China: $45.8 \%$, France: $40 \%$ and Italy: $18.7 \%, \mathrm{p}=n s$ ). The frequency (scored from 0: never to 4: daily) of use of institutional remote systems was significantly different between the three countries (1.5 [1-3] for China, 1 [0-2] for France, 0 [0-0] for Italy, $\mathrm{p}=0.025)$ in particular between China and Italy $(\mathrm{p}=0.019)$. The use of personal remote systems was also significantly different between these countries $(\mathrm{p}=0.0002)$, more frequent in China $(1.5[1-3])$ compared with 0 $[0-1]$ for France $(p=0.0004)$ and to $0[0-0.25]$ for Italy $(p=0.0046)$.

During the COVID-19 pandemic, the frequency of use of institutional and personal remote systems was no longer significantly different between the 3 countries (remote institutional system: Italy: 3 [3-4], France: 3 [3-4], and China: 2.5 [1-3], p =ns and personal remote system: Italy: 2.5 [0-3.25], France: 1 [0-3], and China 3 [1-4], p =ns). The proportion of respondents using official remote systems or phone calls without video for remote clinics was not statistically different between France, Italy, and China (official remote system: China: 66.6\%, France: $62.1 \%$, Italy: $66.6 \%, \mathrm{p}=n s$ and phone call without video: China: $33.3 \%$, France: $43 \%$, and Italy: $13 \%, \mathrm{p}=n s$ ). However, in China, remote personal systems were more often used to manage patients than in other countries (57.1\%, Italy: $20 \%$, France: $5.2 \%, \mathrm{p}<10^{-4}$ ).

Concerning educational activities, the proportion of respondents involved was not statistically different (China: $95.2 \%$, France: $75.9 \%$, and Italy: $68.8 \%, \mathrm{p}=n s$ ). Before the COVID-19 pandemic, the proportion of Chinese respondents who had already experience online teaching was significantly higher ( $82.6 \%$ versus $40.5 \%$ for France and $36.4 \%$ for Italy, $\mathrm{p}=0.003$ ). The respondents who had their teaching activities impacted by COVID-19 pandemic were 95\% for China, 87.8\% for France, and $72.8 \%$ for Italy $(\mathrm{p}=n s)$. During the pandemic, all respondents in China replaced at least part of their course with online teaching (20/ $20)$ compared with $56 \%$ in France and $60 \%$ in Italy $(\mathrm{p}=0.002)$ in particular using interactive online teaching (China: $78.3 \%$, France: $31 \%$, and Italy: $27 \%, \mathrm{p}=0.001$ ).

Concerning remote meetings, a large majority of respondents had already used this system without any statistical difference between countries (China: $90 \%$, France: $87.5 \%$, and Italy: $85.7 \%, \mathrm{p}=n s$ ).

For satisfaction scores (from very unsatisfied: -2 to very satisfied: +2 with a neutral position: 0 ), only the impression on families' and patients' satisfaction for remote clinics had a tendency to be higher in France compared with China (1 [1-1] for France and 1 [0-1] for China, $\mathrm{p}=0.06$, Italy: $1[0.25-1])$. All other satisfaction scores showed no significant difference.

\section{Discussion}

The COVID-19 pandemic blockage has significantly strengthened the use of remote access technologies in medicine. Our study showed that pandemic has increased the shift from classical to remote communication for epilepsy practitioners in all the fields of their activity, namely clinical activity, teaching, and scientific meetings. The satisfaction was acceptable, and almost all responders agreed on a possible future use of remote systems for some of the scientific and educational meetings or for occasional remote clinics excluding first visit.

\subsection{Remote clinics}

Our study demonstrated that during the COVID-19 pandemic, there has been a reduction of face-to-face visits with a replacement for most by remote clinics. In similar situations, remote systems had already been identified as a possible alternative to face-to-face visits, for example, during Ebola or SARS epidemics [10]. In the same way, our study showed an increase of remote clinic frequency use during the pandemic compared with the pre-pandemic period.

Prior work on remote systems in epilepsy has shown notable benefits. A pilot study in Canada compared remote systems to face-to-face clinics showing a decrease of costs of $92.5 \%$ ( $\$ 35.85$ versus $\$ 466$ ) with a satisfaction for patients of $90 \%$ and only $8 \%$ preferring a face-to-face next visit in both groups [11]. The main barriers to remote clinics are the need for clinical examination, technical support, and reimbursement [12]. In our survey, respondents identified the same advantages and barriers, the first visit being the most challenging. In another study comparing the impression of new patients on remote visits with face-to-face visits, patients' perceptions of the neurologist's understanding, their ability to say what they wanted, their confidence in the neurologist, and the usefulness of the visit were similar [13]. However, they stated more difficulties in describing their symptoms and concerns about confidentiality.

In our study, 34 respondents used personal remote system for remote clinics. This raises concerns about privacy and protection. Of note is that the explosion of remote working systems due to COVID19 attracted hackers [14]. One attack, called "Zoom bombing", consists of an unwanted intrusion, causing disruption and possibly disclosure of medical confidentiality. In order to regulate the security of health data during remote clinics, countries have established strict rules such as the Health Insurance Portability and Accountability Act (HIPAA) in the USA [15] and General Data Protection Regulation in EU [16]. Most of the free-access personal remote systems in our study are not HIPAA compliant. This point should be better addressed by health authorities in future development of remote clinics.

\subsection{Online teaching}

Until 2015, attendance in medical classes was correlated with passing the examination [17-19]. Since 2015, however, some studies have found no clear correlation [20,21]. For example, 4 th year medical school students have more absences than 2nd year students due to conferences, meetings, and residency interviews, but unlike personal absences, this type of absence is not significantly associated with lower academic test scores [22]. This is likely due to the improvement of means of communication that have enabled the students to fill in the gaps. In a recent study using a combined approach between online teaching and face-to-face interactive medical course, online teaching attendance was higher than face-to-face, and the exam score was correlated to online teaching attendance. Ninety-eight percent were satisfied with this teaching, and 93\% wished to extend it to the entire second cycle [23]. This is a good illustration of the change of perspective that is taking place in undergraduate and postgraduate university education. Factors associated with a good adherence to online teaching are mainly the quality of the technical system, support system, learner and instructor, and the perceived usefulness [24,25]. The advantages and disadvantages identified by the providers in our study were in line with the literature, i.e., on the one hand, a greater flexibility, an increase of the dissemination of knowledge, a decrease of travel cost and time, and better accessibility, on the other hand, less peer-to-peer exchange and feedback difficulties, including nonverbal communication [26]. 


\subsection{Remote meetings}

In the symposia and meetings, the same advantages and disadvantages as with teaching were identified, but the proportion of respondents who recommended this method for the future were lower than for clinics and teaching. The use of remote systems seemed to be more adapted for research networks and workshops than congresses. But during the COVID-19 pandemic, the European Academy of Neurology replaced its congress by a virtual meeting free-of-charge. With more than 40,000 participants, they claimed this to be "the biggest neurology meeting ever" [27]. A virtual congress allows for lower prices, time savings, and a greater dissemination of knowledge both to and from all over the world. However, the respondents interviewed stressed the importance of face-to-face for the development of collaborative projects.

\subsection{Difference between China, France, and Italy}

Our questionnaire highlighted, before the COVID-19 epidemic, a stronger experience of remote systems in China compared with France and Italy. This may be due to previous epidemic crisis in China, a larger geographic area of China compared with France and Italy, and a lower density of neurologists and child neurologists ( 0.1 and 0.02 per 100,000 persons for neurologists and child neurologists, respectively in south-east Asia region versus 6.6 and 0.8 per 100,000 persons in Europe [28]). Indeed, prior to the COVID-19 pandemic, some studies and reviews identified remote clinics in the field of epilepsy as an opportunity in rural regions and in resource-poor setting where the access to a specialist is an important barrier to epilepsy diagnosis and treatment [29-36]. However, the COVID-19 pandemic seemed to have accelerated the shift towards the implementation of remote clinics and had enabled France and Italy to fill the gap with a strong development of remote patient management tools.

\subsection{Study limitations}

The sample of this study was small, but respondents completed the survey just after the COVID-19 in China and during the COVID-19 pandemic and lock down in other countries, giving to this survey a value of "almost" real-time responses. Responses were from many countries around the world thanks to the involvement of international societies. We cannot rule out the presence of a selection bias since this questionnaire was sent online. However, we believe that this study can present a picture about practitioners' opinion on remote work in epilepsy and help to develop future perspectives. In addition, a significant proportion of respondents in our sample focus on pediatric care. The use of remote clinics in this population is probably easier than in adults. Indeed, parents may be able to successfully complete a visit on their child's behalf but adults with cognitive impairment or other limitations may have more difficulty negotiating the technical requirements of such a visit. Finally, we did not request a detailed description of the applied methods of online teaching. The survey aimed to have answers on the three activity fields of the respondents without adding much details relatively long survey.

\section{Conclusion}

The COVID-19 pandemic has increased the shift from classical to remote communication for epilepsy practitioners in all the fields of their activity, namely clinical activity, teaching, and scientific meetings. The advances of these methods of communication have allowed a rapid adaptation to confinement policies using their flexibility and their accessibility. This allowed a maintained link between practitioners and patients, professors and students, and between groups and colleagues. The satisfaction was acceptable, and almost all responders agreed on a possible future for remote work, for some of the scientific and educational meetings or for occasional teleconsultations. In addition, the positive ecological impact of such approaches might be interesting in addition to the economic impact on health and academic costs. It is likely that in "the world after COVID", the shift process to the implementation of these new modes of communication is moving forward, although the balance between face-to-face and remote work has yet to be determined in our different fields of activities, and the long-term benefit of such shift to virtual interaction should be evaluated.

\section{Disclosure of conflicts of interest}

M. Kuchenbuch, G D'Onofrio, Y. Jiang, ZM Grinspan, J Wilmshurst and R Nabbout have any conflict of interest to disclose. S Dupont has received honoria from EISAI, UCB, GW, Novartis, Advicenne and Shire. E Wirrell has acted as an investigator for GW Pharma and Zogenix and has received consulting fees from Biocodex and Biomarin. S Auvin has served as consultant or received honoraria for lectures from Arvelle therapeutics, Biocodex, Eisai, GW Pharma, Novartis, Nutricia, UCB Pharma, Zogenyx. He has been investigator for clinical trials for Advicenne Pharma, Eisai, UCB Pharma and Zogenyx. A Arzimanoglou has served as consultant, received honoraria for lectures from Arvelle therapeutics, Eisai, GW Pharma, UCB Pharma and Zogenix. On behalf of his Instiitution he has been investigator for clinical trials sponsored by Eisai, GW, UCB Pharma and Zogenix. JH Cross has acted as an investigator for studies with GW Pharma, Zogenix, Vitaflo and Marinius. She has been a speaker and on advisory boards for GW Pharma, Zogenix, and Nutricia; all remuneration has been paid to her department. Her research is supported by the National Institute of Health Research (NIHR) Biomedical Research Centre at Great Ormond Street Hospital, NIHR, EPSRC, GOSH Charity, ERUK, the Waterloo Foundation. N Specchio has acted as an investigator for studies with Zogenix, Marinus, Biomarin, and Livanova, and has received consulting fees from Zogenix, Biomarin, Arvelle, Livanova.

\section{Acknowledgment}

The authors wish to thank the practitioners who participated in this study and the networks without whom this study could not have been carried out, namely the International League Against Epilepsy, the International Child Neurology Association, the French League Against Epilepsy, the French Society of Pediatric Neurology, and the ERN EpiCARE network. Rima Nabbout was supported by State funding from the Agence Nationale de la Recherche under "Investissements d'avenir" program (ANR-10-IAHU-01) and the "Fondation Bettencourt Schueller".

\section{Funding}

This research was supported by the Agence Nationale de la Recherche under "Investissements d'avenir" program (ANR-10-IAHU01 ) and the "Fondation Bettencourt Schueller", Paris, France.

\section{Appendix A. Supplementary data}

Supplementary data to this article can be found online at https://doi. org/10.1016/j.yebeh.2020.107376.

\section{References}

[1] Lai SL, Hsu MT, Chen SS. The impact of SARS on epilepsy: the experience of drug withdrawal in epileptic patients. Seizure. 2005;14:557-61. https://doi.org/10. 1016/j.seizure.2005.08.010.

[2] Wechsler LR. Advantages and limitations of teleneurology. JAMA Neurol. 2015;72: 349-54. https://doi.org/10.1001/jamaneurol.2014.3844.

[3] Australasian Telehealth Society. National digital health strategy; 2017; 1-63.

[4] Scotland ' S Digital Health \& Care Strategy n.d.

[5] Danish Ministry of Health. Digital Health Strategy 2018-2022; 2018. 
[6] South African National Department of Health. National Digital Health Strategy for South Africa. 2019-2024; 2019.

[7] 3.5.1. RDCT. A language and environment for statistical computing. R Found Stat Comput, 2. ; 2018https://www.R-project.orghttp://www.r-project.org. accessed May 22, 2020

[8] World Health Organization. Coronavirus disease (COVID-19) situation report-111; 2020.

[9] Johns Hopkins University \& Medicine. Coronavirus COVID-19 global cases by Johns Hopkins Coronavirus Resource Center. https://coronavirus.jhu.edu/map.html; 2020. [Accessed 9 June 2020].

[10] Ohannessian R. Telemedicine: potential applications in epidemic situations. Eur Res Telemed. 2015;4:95-8. https://doi.org/10.1016/j.eurtel.2015.08.002.

[11] Ahmed SN, Mann C, Sinclair DB, Heino A, Iskiw B, Quigley D, et al. Feasibility of epilepsy follow-up care through telemedicine: a pilot study on the patient's perspective. Epilepsia. 2008;49:573-85. https://doi.org/10.1111/j.1528-1167.2007.01464.x.

[12] Ahmed SN, Wiebe S, Mann C, Ohinmaa A. Telemedicine and epilepsy care-a Canada-wide survey. Can J Neurol Sci. 2010;37:814-8. https://doi.org/10.1017/ S0317167100051490.

[13] Chua R, Craig J, Wootton R, Patterson V. Randomised controlled trial of telemedicine for new neurological outpatient referrals. J Neurol Neurosurg Psychiatry. 2001;71: 63-6. https://doi.org/10.1136/jnnp.71.1.63.

[14] Hackers' new target during pandemic: video conference calls n.d. https://apnews. com/94f4446acae487e1eb7cc85e2c176908 (accessed May 26, 2020).

[15] Caplan RM. HIPAA. Health Insurance Portability and Accountability Act of 1996. Dent Assist. 2003;72:6-8.

[16] European Parliament and Council of the European Union. Regulation on the protection of natural persons with regard to the processing of personal data and on the free movement of such data, and repealing Directive 95/46/EC (Data Protection Directive). Off J Eur Union. 2016:L 119:1-88.

[17] Credé M, Roch SG, Kieszczynka UM. Class attendance in college: a meta-analytic review of the relationship of class attendance with grades and student characteristics. Rev Educ Res. 2010;80:272-95. https://doi.org/10.3102/0034654310362998.

[18] Deane RP, Murphy DJ. Student attendance and academic performance in undergraduate obstetrics/gynecology clinical rotations. J Am Med Assoc. 2013;310:2282-8. https://doi.org/10.1001/jama.2013.282228.

[19] Desalegn AA, Berhan A, Berhan Y. Absenteeism among medical and health science undergraduate students at Hawassa University, Ethiopia. BMC Med Educ. 2014;14: 1-11. https://doi.org/10.1186/1472-6920-14-81.

[20] Kauffman CA, Derazin M, Asmar A, Kibble JD. Relationship between classroom attendance and examination performance in a second-year medical pathophysiology class. Adv Physiol Educ. 2018;42:593-8. https://doi.org/10.1152/advan.00123.2018.

[21] Eisen DB, Schupp CW, Isseroff RR, Ibrahimi OA, Ledo L, Armstrong AW. Does class attendance matter? Results from a second-year medical school dermatology cohort study. Int J Dermatol. 2015;54:807-16. https://doi.org/10.1111/ijd.12816.
[22] Cruz TE, Riddell R, Gamaldo CE, Strowd RE, Oakley C, Salas RME. The impact of student absences on grade outcomes in a neurology clerkship setting. MedEdPublish. 2019;8. https://doi.org/10.15694/mep.2019.000147.1.

[23] Vodovar D, Ricard JD, Zafrani L, Weiss E, Desrentes E, Roux D. Assessment of a newly-implemented blended teaching of intensive care and emergency medicine at Paris-Diderot University. Rev Med Interne. 2020. https://doi.org/10.1016/j. revmed.2019.12.021.

[24] Al-Fraihat D, Joy M, Masa'deh R, Sinclair J. Evaluating E-learning systems success: an empirical study. Comput Human Behav. 2020;102:67-86. https://doi.org/10.1016/j. chb.2019.08.004.

[25] Cidral WA, Oliveira T, Di Felice M, Aparicio M. E-learning success determinants: Brazilian empirical study. Comput Educ. 2018;122:273-90. https://doi.org/10. 1016/j.compedu.2017.12.001.

[26] Choudhury S, Pattnaik S. Emerging themes in e-learning: a review from the stakeholders' perspective. Comput Educ. 2020;144:103657. https://doi.org/10.1016/j. compedu.2019.103657.

[27] Marson AG, Bassetti CLA. EAN congress highlights challenges - predict, prevent, repair. Nat Rev Neurol. 2020. https://doi.org/10.1038/s41582-020-0384-9.

[28] WHO. Atlas - country resources for neurological disorders. Atlas Ctry Resour Neuro Disord. 2017;30:175-8. https://doi.org/10.5860/CHOICE.42Sup-0341.

[29] Sarfo FS, Adamu S, Awuah D, Ovbiagele B. Tele-neurology in sub-Saharan Africa: a systematic review of the literature. J Neurol Sci. 2017;380:196-9. https://doi.org/ 10.1016/j.jns.2017.07.037.

[30] Shankar R, Newman C, McLean B, Anderson T, Obe JH. Can technology help reduce risk of harm in patients with epilepsy? Br J Gen Pract. 2015;65:448-9. https://doi. org/10.3399/bjgp15X686413.

[31] Velasquez SE, Chaves-Carballo E, Nelson EL. Pediatric teleneurology: a model of epilepsy care for rural populations. Pediatr Neurol. 2016;64:32-7. https://doi.org/10. 1016/j.pediatrneurol.2016.08.001.

[32] Rajbhandari H, Joshi S, Malakar S, Paudel P, Jain P, Uppadaya K, et al. Epilepsy field workers, a smartphone application and telephone telemedicine: safe and effective epilepsy care in rural Nepal. Seizure. 2019;64:54-8. https://doi.org/10.1016/j.seizure.2018.12.005.

[33] Patterson V, Bingham E. Telemedicine for epilepsy: a useful contribution. Epilepsia. 2005;46:614-5. https://doi.org/10.1111/j.1528-1167.2005.05605.x.

[34] Patterson V. Telemedicine for epilepsy support in resource-poor settings. Front Public Heal. 2014;2:8-11. https://doi.org/10.3389/fpubh.2014.00120.

[35] Patterson V. Managing epilepsy by telemedicine in resource-poor settings. Front Public Heal. 2019;7:1-6. https://doi.org/10.3389/fpubh.2019.00321.

[36] Kissani N, Lengané YTM, Patterson V, Mesraoua B, Dawn E, Ozkara C, et al. Telemedicine in epilepsy: how can we improve care, teaching, and awareness? Epilepsy Behav. 2020;103. https://doi.org/10.1016/j.yebeh.2019.106854. 